\title{
EDITOR'S INTRODUCTION - Volume 2 no 2
}

\author{
David.Palfreyman@zu.ac.ae - Zayed University, Dubai
}

In this issue of our online publication we continue our effort to provide a variety of perspectives and content relevant for those working in tertiary education in the Arabian Gulf region.

As well as academic papers concerned with empirical study and conceptual analysis, as in previous issues, we are also introducing the perspective of the Gulf learner by publishing for the first time student-written pieces on the theme "A Course from which I Learned a Lot". We hope to make this a regular feature of our journal, and students from other institutions in the Gulf are invited to submit pieces of writing on this theme.

We are also reflecting the interdisciplinary focus of the journal and an emphasis on critical use of literature on higher education with our first "3-D" book review, in which three academics from different disciplines review a cross-disciplinary university textbook on academic language skills from their own subject perspectives.

The theme of students" language skills is one which often provokes discussion in Gulf universities and colleges, and Sadia Ali"s paper examines her own students" performance in one area where these skills are under scrutiny every day: in e-mail communication with professors. The author considers some ways in which teachers in all subjects could help to support students" development in this area.

Reflection (in students and in teachers) is another key theme in current debates. Ghassoub Mustafa provides a comprehensive review of concepts related to the "reflective educator" " a role which many professors and instructors in higher education would no doubt aspire to. The concepts reviewed in this paper are also highly relevant to the promotion of reflective abilities in our students, and this latter theme is picked up in the review of Jennifer Moon"s recent book A handbook of reflective and experiential learning: Theory and practice.

Finally, the theme of students" construction of knowledge is evident not only in the two student-written pieces in this issue, but also in Brian Hinton"s review of a constructivist approach to teaching the sciences, and explanation of how he has put this approach into practice in teaching a computing concept.

We hope that you will find this issue interesting and relevant to your work and concerns; and we welcome feedback from readers as input for future issues of the journal. 